\title{
La mediación como alternativa de solución de los conflictos empresariales en Chile. Razones y mecanismos para su regulación*
}

\author{
Eduardo Jequier Lebuedé**
}

\begin{abstract}
RESUMEN
El presente trabajo analiza las características de la mediación y las razones que explican la tendencia actual que muestran los ordenamientos jurídicos comparados, que la han incorporado como mecanismo de solución de conflictos mercantiles y civiles de carácter patrimonial. Se revisa la situación actual de la mediación comercial en Chile, la constitucionalidad de su manifestación forzosa y los diversos mecanismos utilizados en el derecho comparado, para plantear finalmente la conveniencia de una regulación expresa de la misma, que incluya fórmulas para potenciar su uso e incentivar la colaboración de buena fe de las partes.
\end{abstract}

Mediación comercial - mediación obligatoria - mediación empresarial

\section{The mediation like an alternative for the solution of enterprise conflicts in Chile. Reasons and mechanisms for his regulation}

\begin{abstract}
This paper analyzes the characteristics of the mediation and the reasons behind the current tendency in comparative legal systems, which have incorporated it as a mechanism for solving commercial and civil disputes with an economic nature. It analyzed the current situation of commercial mediation in Chile, the constitutionality of their forced manifestation and the various mechanisms used in comparative law, to finally raise the desirability of an explicit provision of it, including ways to promote their use and to encourage the cooperation in good faith of the parties.
\end{abstract}

Commercial mediaton - mandatory mediaton - business mediaton

* El presente trabajo se realiza en el marco del Proyecto Fondecyt Regular 2015, No 1150087 , titulado "La mediación en asuntos comerciales como instrumento de competitividad y desarrollo empresarial en Chile. Premisas para una propuesta de lege ferenda", del cual el autor es investigador responsable; y del Proyecto Anillo SOC 1406, denominado "Mecanismos Alternativos de Solución de Conflictos como Herramienta de Modernización de la Justicia. Construcción dogmática a partir de un análisis multidisciplinario”, en el cual el autor es investigador asociado.

** Mg. en Derecho de la Empresa, Pontificia Universidad Católica de Chile. Doctor en Derecho, Universitat de Valencia. Profesor de Derecho Comercial, Universidad de los Andes, Chile. Email: ejequier@ uandes.cl.

Artículo recibido el 30 de junio de 2015 y aceptado para su publicación el 21 de enero de 2016. 


\section{INTRODUCCIÓN}

\section{$\mathrm{L}$} uego de transitar por algunas experiencias puntuales, como el Programa de Conciliación y Mediación Laboral de los años 2002 a 2004 , la mediación en Chile se incorporó definitivamente a partir de la Ley $\mathrm{N}^{\circ} 19.698$ (D.O. de 30 de agosto de 2004), para resolver determinados asuntos del ámbito familiar. Posteriormente, la Ley $\mathrm{N}^{\mathrm{o}} 19.966$ (D.O. de 9 de septiembre de 2004), arts. 43 y ss., incorporó la mediación previa obligatoria en materia de salud, aportando incluso la primera y única definición legal de mediación que conoce el ordenamiento jurídico chileno.

Sin embargo, y como contrapunto del notorio desarrollo que ha tenido la mediación familiar en Chile ${ }^{2}$, el legislador ha postergado hasta aquí toda y cualquier referencia a la solución mediada de asuntos comerciales y civiles, mostrando así un claro rezago respecto de una tendencia comparada que ve en aquella un mecanismo autocompositivo de soluciones rápidas, de menor costo, ajustadas a las necesidades de cada parte y, principalmente, a las complejidades propias de cada conflicto empresarial.

Pese a la encomiable labor de algunos entes públicos y privados que ofrecen actualmente procedimientos de mediación de asuntos patrimoniales, como el Programa

${ }^{1}$ Se trata del "Programa de Conciliación y Mediación”, implementado por el Ministerio del Trabajo y Previsión Social y la Dirección del Trabajo. En sus dos primeros años de ejecución (2002 y 2003) la tasa de variación de usuarios se incrementó en 18,9\%. De ese porcentaje, el 62\% correspondió a mediaciones, orientadas a trabajadores con relación laboral vigente y empleadores que están en conflicto. En cuanto a sus resultados, la Conciliación (destinada a los casos de trabajadores con contratos concluidos) logró un 58,71\% de resolución efectiva en el año 2002, mientras que en el 2003 llegó al 60,45\%. La Mediación, por su parte, se aplicó el 2002 a 268 conflictos, con 187 resultados positivos que terminaron en acuerdo (70\%). En el 2003 se realizaron 430 mediaciones, con 289 resultados positivos (67\%). Vid. "Programa de Conciliación y Mediación. Ministerio del Trabajo y Previsión Social / Dirección del Trabajo. Informe Final de Evaluación”, disponible en: http://www.dipres.gob.cl/574/articles-14932_doc_pdf.pdf Consultado el 23 de junio de 2015 .

${ }^{2}$ Según un estudio realizado en el 2006 por la Universidad de Concepción, el Índice de Satisfacción Global de los usuarios del sistema de mediación familiar licitado, entre febrero y julio de ese año, reveló solo 9,714\% de usuarios insatisfechos, mientras que la satisfacción global alcanzó al 51,62\%. Por temas, los mayores índices de satisfacción neta se dieron para la "Calidad de Atención e Información Entregada por el Mediador" y para la "Calidad de Servicio", en donde se observó el máximo nivel de satisfacción. Solo en la evaluación del proceso de mediación se obtuvo una satisfacción neta negativa, aunque explicada principalmente por los costos de pasajes, distancias al lugar de atención del mediador y el número de sesiones. Vid. Universidad de Concepción, Facultad de Ciencias Económicas y Administrativas (2006): Informe de "Calidad de Servicio Mediación Licitado por el Ministerio de Justicia", p. 6. Disponible en: http://www. mediacionchile.cl/portal/phocadownload/estudios/EST_6.pdf (Consultado el 22 de junio de 2015). Siete años después, el 2013, un nuevo estudio, realizado por la misma Universidad, mostró un notorio incremento en los índices de satisfacción a nivel nacional, con una calificación promedio de 6,24, en una escala de 1 a 7. En la construcción del Índice de Satisfacción se consideraron siete dimensiones, en seis de las cuales la calificación promedio es superior a 6,0. Solo una dimensión, la Satisfacción del Usuario, presentó una calificación inferior a 6,0, (5,70), explicado principalmente por la baja calificación que los usuarios asignan a la relación después de la mediación (4,84). Vid. Universidad de Concepción, Facultad de Ciencias Económicas y Administrativas (2013): "Estudio de Satisfacción de Usuarios/as del Sistema Nacional de Mediación. Año 2013”, p. 148. Disponible en: File://C:/Users/78082887/Downloads/informe\%20final\%20encuesta\%20 udec\%202013\%20(1).pdf (Consultado el 22 de junio de 2015). 
de Mediación Vecinal/Comunitaria a cargo del Ministerio de Justicia ${ }^{3}$ y la que ofrece el Centro de Mediación y Arbitraje de la Cámara de Comercio de Santiago, lo concreto es que en Chile la cultura mediadora en asuntos mercantiles es prácticamente nula o al menos rudimentaria, si se compara con la práctica de otros países. No debe extrañar, por lo mismo, que la tendencia casi intuitiva de empresarios y abogados, al momento de optar entre el litigio y la mediación como vías alternativas de solución de un conflicto, se decante invariablemente -o al menos comúnmente- por la primera, con los costos e ineficiencias que ello pudiere reportar. En las antípodas de esta realidad se encuentran en cambio los sistemas comparados que han optado decididamente por la mediación, como ocurre con los de origen anglosajón ${ }^{4}$, donde la mediación ha sido llevada incluso a las pantallas del cine en películas como "The Social Network", que muestra la negociación y acuerdo que tuvo lugar en el conflicto surgido en el 2008 entre los cofundadores de Facebook ${ }^{5}$, y que permitió dilucidar los destinos y el control de una compañía hoy billonaria.

En el último tiempo, en efecto, países con filiaciones jurídicas muy distintas, como la anglosajona y europeo-continental, han incorporado expresamente a sus respectivas legislaciones la mediación para la solución de conflictos empresariales de carácter patrimonial, como una forma de evitar la excesiva judicialización de los mismos y los costos prohibitivos que ello conlleva para el quehacer de los negocios. Todavía más, y pese a la raigambre esencialmente voluntaria de la mediación, como se dijo supra, razones de política judicial y el anhelo siempre latente de minimizar los costos económicos y sociales de una litigiosidad excesiva, han llevado a algunas legislaciones comparadas a imponer la mediación como un estadio previo y necesario para acceder al proceso; pero no solo en el ámbito de los asuntos de familia o de salud como ocurre en $\mathrm{Chile}^{6}$, donde la obligatoriedad encuentra su justificación en el carácter supraindividual de los intereses involucrados, sino en aquellos conflictos de carácter mercantil que, como tales, traen causa en materias de orden patrimonial que son enteramente disponibles para ellas.

A partir de algunos datos empíricos que hemos obtenido con ocasión de la realización de este trabajo, y de la información estadística que proporcionan a su vez algunos estudios realizados en Chile y en el extranjero respecto del fenómeno de la litigiosidad en materias civiles y comerciales, apuntamos a dilucidar, entonces, las razones que explican el notorio desarrollo que ha experimentado la mediación en asuntos mercantiles en los últimos años, enfocándonos especialmente en la fórmula obligatoria previa que, con matices, ha sido recogida transversalmente por países con distintas tradiciones y sistemas jurídicos. Es el caso, como veremos, de Alemania e Italia, ambos tributarios

\footnotetext{
${ }^{3}$ Hasta la fecha de presentación de este trabajo, ha sido imposible obtener cifras estadísticas por parte del Programa de Mediación Vecinal.

${ }^{4}$ Así por ejemplo, Reino Unido regula la mediación en las Civil Procedures Rules, de 1998.

${ }^{5}$ La negociación permitió poner fin al conflicto entre Mark Suckerberg; los gemelos Tyler y Cameron Winklevoss y el amigo de ambos, Divya Narenda, quienes acusaron al primero de haberles robado la idea de la red social; y Eduardo Saverin, quien financió los primeros pasos de lo que en ese entonces no era más que una intranet en la Universidad de Harvard.

${ }^{6}$ Véanse los artículos 106 de la Ley No 19.698 y 43 y ss. de la Ley № 19.966, respectivamente.
} 
del Derecho continental europeo; de países del common law como Inglaterra y los EE. UU. de Norteamérica (este último mediante la figura del court annexed mediation); y también en algunas legislaciones Latinoamericanas que, si bien no serán analizadas en esta oportunidad, constituyen también una clara muestra de la tendencia global del fenómeno apuntado ${ }^{7}$ (a partir de ahí revisaremos la viabilidad -primero-y la conveniencia -después- de implementar legalmente la mediación comercial en el derecho chileno, incluida la fórmula obligatoria conocida ya en los ámbitos antes referidos (familia y salud), pero aun al debe ${ }^{8}$ respecto de materias de índole mercantil e incluso de carácter mixto, como ocurre con las relaciones de consumo?.

Por último, y a modo de aclaración general, en lo que sigue nos referiremos indistintamente a la "mediación empresarial" como concepto que abarca por igual los conflictos surgidos de relaciones que son mercantiles para todas las partes involucradas; mixtas o de doble carácter; o puramente civiles, por no concurrir ninguno de los actos de comercio del art. $3^{\circ}$ del Código de Comercio, ni directamente ni por accesoriedad.

\section{EL PORQUÉ Y PARA QUÉ DE LA MEDIACIÓN COMERCIAL}

Como se dijo supra, durante los últimos años la mediación de asuntos mercantiles ha experimentado un notorio impulso legislativo, con sistemas que la han incorporado incluso de forma obligatoria y, en ciertos extremos, como requisito de procesabilidad de los conflictos respectivos. Las razones para ello son variadas, aunque pueden focalizarse en torno a dos grandes núcleos: la desjudicialización, como mecanismo de descarga de los tribunales de justicia; y la eficiencia económica en la solución de los conflictos, como vía de reasignación de recursos escasos hacia fines de mayor rentabilidad social.

\section{Algunos datos estadísticos en el sistema judicial chileno}

Como se señala en el "Perfil de Proyecto" del Programa BID sobre "Apoyo a la Reforma Judicial"10, aprobado en julio de 2010, según el "Reporte Sobre la Justicia en las Américas del Centro de Estudios de Justicia de las Américas" (CEJA), Chile es

${ }^{7}$ Vid. infra, notas 27 a 30.

${ }^{8}$ Acusamos aquí una deuda más no un vacío total de la legislación vigente en esta materia. Así queda en evidencia al revisar por ejemplo las normas de la reciente Ley concursal, $\mathrm{N}^{\circ} 20.720$, sobre Reorganización y Liquidación de Empresas y Personas (D.O. de 9 de enero de 2014). Según el art. 265 inc. $2^{\circ}$ de la ley, en efecto, El Superintendente, o quien este designe, actuará como facilitador, ayudando a las partes a adoptar una solución satisfactoria, asignándole así un claro rol de mediador. El camino a seguir en las restantes materias mercantiles, entonces, ya está delineado y solo resta definir su trazado normativo final.

${ }^{9}$ El art. $55 \mathrm{~N}^{\circ} 3$ de la Ley $\mathrm{N}^{\circ} 19.496$ contempla únicamente la figura del mediador financiero, a propósito del otorgamiento del denominado "Sello SERNAC", el que se concede -dice-a aquellos proveedores referidos en el inciso $1^{\circ}$ de la misma disposición.

${ }^{10}$ Proyecto BID N ${ }^{\circ}$ CH-L1058, "Perfil de Proyecto", p. 1 (Disponible en http://idbdocs.iadb.org/ wsdocs/getdocument.aspx?docnum =35080924) El contrato de Préstamo es el N ${ }^{\circ}$ 2497/OC-CH, de 28 de enero de 2011, aprobado por del Banco Interamericano de Desarrollo -BID- mediante Resolución DE-235/10. 
el país de América Latina con la tasa más alta de litigiosidad, con un ingreso anual de causas que sigue aumentando (en 2008 ingresaron $13 \%$ más de causas que en 2007). Este aumento de causas - dice el mismo Perfil-, ha sido enfrentado y contrarrestado con un incremento sostenido del presupuesto judicial, que entre 2003 y 2007 aumentó en 50\%, y con una mayor capacidad para poner término a las causas pendientes, sin considerar, por lo mismo, la utilidad que presentan en esta misma línea mecanismos alternativos de solución de conflictos civiles y comerciales como la mediación.

Según las estadísticas publicadas por el Poder Judicial, de 126.219 causas ingresadas a las Cortes de Apelaciones del país entre 2010 y 2012 (o sea, sin contar los ingresos del sistema de turnos en los Juzgados de Letras), el 20,4\% fueron de naturaleza civil y comercial. A ellas se suma 49,3\% de causas de diversa índole que no encajan en los ingresos de la jurisdicción de familia, laborales y penales $(v . g r \text {. recursos de protección })^{11}$, observándose además una tendencia al aumento de ingresos, que en el período 2011-2012 alcanzó 20,69\% y en donde el mayor impacto lo generan precisamente las causas civiles ${ }^{12}$.

En concreto, durante el 2011 el ingreso total de causas a nivel nacional alcanzó a 2.063.804, de las cuales el $90 \%$ fueron procedimientos ejecutivos y gestiones preparatorias de la vía ejecutiva, el $3 \%$ correspondió a procedimientos ordinarios y un 2\% a juicios sumarios.

En cuanto al primer grupo de causas - las ejecutivas y preparatorias-, es bien conocida la intención del Proyecto de Código Procesal Civil, en su redacción inicial, en cuanto a desjudicializar y privatizar el sistema de cobranzas, para entregarlo al denominado "oficial de ejecución" (al menos en una primera fase). Dicha iniciativa, sin embargo, ha sido decididamente criticada y su destino es por lo mismo incierto, por lo que no nos ocuparemos por ahora de este grupo de causas ni de la función que podría cumplir en ellas la mediación.

Distinto es el caso de los grupos restantes (causas no masivas sometidas por lo general a los procedimientos ordinario y sumario), pues es allí en donde la mediación puede contribuir al logro de los fines que mencionábamos supra.

Del universo de ingresos que acabamos de mencionar, acerca de procedimientos ordinarios y sumarios, y para definir concretamente (a) de qué tipo de materias conocen los juzgados civiles, (b) quiénes son los litigantes que acuden a la jurisdicción y (c) cuál es la cuantía promedio de tales asuntos, durante el 2013 el Ministerio de Justicia realizó un interesante estudio estadístico respecto de las causas ingresadas durante el 2011 al $15^{\circ}$ Juzgado de Letras de Santiago, el que fue tomado como muestra representativa de la situación de los restantes tribunales civiles de la misma jurisdicción ${ }^{13}$. Los datos de

11 “Estadísticas Judiciales 2010-2012”, p. 8, en: http://www.pjud.cl/documents/10179/94044/ Estadisticas + Judiciales + 2010+-2012.pdf/575e571c-ec8f-4f6a-971a-9c35adf435d5?version = 1.1 . Consultada el 3 de junio de 2015.

12 Ibid., p. 45.

${ }^{13}$ Ministerio de Justicia (2013): “Tasas Judiciales. Panel de Expertos. Informe Final”, p. 12. Disponible en: http://rpc.minjusticia.gob.cl/media/2013/07/Informe-Final-Tasas-Judiciales.pdf. Consultada el 04 de junio de 2015 . 
dicho estudio, que incluyó a su vez un índice de asuntos a cargo de la Corporación de Asistencia Judicial, pueden sintetizarse de la siguiente forma:

a) En cuanto al tipo de juicios según materia, $74 \%$ de los casos correspondió a cobro de pesos, seguido de $8 \%$ de indemnización de perjuicios y $6 \%$ de acciones de prescripción.

b) La cuantía promedio de los procedimientos ordinarios -principalmente cobro de pesos- alcanzó casi los $\$ 19.000 .000$, con un piso de $\$ 36.000$; mientras que en los juicios de indemnización de perjuicios alcanzó a poco más de $\$ 53.000 .000$, con un piso de $\$ 5.000 .000$.

c) En cuanto al tipo de litigante que acude a los tribunales de justicia se detectó que en el caso de los juicios ordinarios el $82 \%$ de ellos fueron personas jurídicas y el $18 \%$ restante personas naturales. En los procedimientos sumarios (principalmente juicios de arrendamiento y acciones de precario) el $39 \%$ fueron personas jurídicas y el $61 \%$ personas naturales, mayoritariamente mujeres.

d) Tratándose de la asistencia judicial gratuita y, más específicamente, de la que presta la Corporación de Asistencia Judicial a personas que gozan del beneficio del privilegio de pobreza ${ }^{14}$, el $31 \%$ de las causas civiles que atiende dicha Corporación, que representan a su vez el $15 \%$ del total de sus ingresos, corresponden a asuntos patrimoniales de muy baja cuantía y de lato conocimiento; el $20 \%$ corresponde a causas voluntarias; el $19 \%$ son causas ejecutivas o en etapa de cumplimiento; el $11 \%$ son juicios de arrendamiento y el $7 \%$ de precario, ambos tramitados conforme al procedimiento sumario; y el $7 \%$ restante corresponde a otros asuntos civiles $^{15}$. La duración de esas causas, a su vez, va desde un mínimo de 360 días y un máximo de 420 días en el caso de las sometidas al procedimiento sumario; y de 560 a 780 días las de más larga duración, normalmente procedimientos ordinarios.

De las cifras apuntadas puede concluirse fácilmente que la incorporación de mecanismos alternativos de solución de conflictos como la mediación, que permitan reducir

${ }^{14}$ Según el art. $2^{\circ}$ de la Ley $N^{\circ} 17.995$, de1981, la finalidad de las corporaciones de asistencia judicial es prestar asistencia jurídica y judicial gratuita a las personas de escasos recursos, las que se seleccionan según las pautas siguientes: a) Personas con ingreso autónomo per cápita del hogar igual o inferior a 3 UF ingresan automáticamente; b) Personas que con un grupo familiar que presente un ingreso autónomo per cápita entre 3 UF a 12 UF, se evaluará la capacidad de pago. Si esta es inferior o igual a 2,5 UF, será beneficiario de patrocinio judicial. Si la capacidad de pago es superior, el usuario quedará excluido del servicio de patrocinio judicial; c) Usuarios que presenten un ingreso autónomo per cápita superior a 12 UF, por regla general quedarán excluidos del servicio del patrocinio judicial, con excepción de aquellos que declaren gastos de salud originados por enfermedad de alto costo, a los cuales se les aplicará el criterio de la capacidad de pago, ingresando al servicio si es igual o inferior a 2,5 UF (Ministerio de Justicia [2013]: "Tasas Judiciales. Panel de Expertos. Informe Final”, p. 10. Disponible en: http://rpc.minjusticia.gob.cl/media/2013/07/ Informe-Final-Tasas-Judiciales.pdf. Consultada el 4 de junio de 2015).

${ }^{15}$ Ibid. 
la creciente litigiosidad y la demora que muestra el sistema judicial en el ámbito civil y mercantil, resultan no solo atractivos sino necesarios; pero no solo por razones de política judicial y de sobrecarga estructural del engranaje jurisdiccional estatal, sino también por factores de economía de costos y de eficiencia económica en la solución de los conflictos.

Por una parte, el costo de estimular todo el aparataje judicial, para solucionar asuntos de baja cuantía o, en último término, conflictos que bien podrían resolverse con un acercamiento mediado entre las partes, involucra una desviación de recursos estatales hacia fines de muy baja rentabilidad social.

Por otro lado, y como se muestra en el siguiente cuadro ${ }^{16}$, en cifras del año 2013 -muy conservadoras por cierto- para las partes el costo básico de litigar asciende en general a la suma aproximada de $\$ 346.000$, sin contar los honorarios de los abogados y gastos extraordinarios como inscripciones, peritajes y otros, lo que hace económicamente inviable la vía jurisdiccional, judicial o arbitral.

\begin{tabular}{|c|c|c|}
\hline \multicolumn{2}{|c|}{ Escritura pública de mandato judicial para presentar demanda } & $\$ 15.000$ \\
\hline \multirow{4}{*}{ Notificación demanda } & Búsquedas negativas & $\$ 15.000$ \\
\hline & Búsquedas positivas & $\$ 15.000$ \\
\hline & Notificación art. 44 & $\$ 20.000$ \\
\hline & Notificación personal & $\$ 30.000$ \\
\hline \multirow{2}{*}{ Notificación llamado a conciliación } & Demandante & $\$ 15.000$ \\
\hline & Demandado & $\$ 20.000$ \\
\hline \multirow{2}{*}{ Notificación autos de prueba } & Demandante & $\$ 15.000$ \\
\hline & Demandado & $\$ 20.000$ \\
\hline \multirow{2}{*}{ Absolución de posiciones } & Citación & $\$ 20.000$ \\
\hline & Absolución & $\$ 30.000$ \\
\hline \multirow{2}{*}{ Testimonial } & Citación & $\$ 20.000$ \\
\hline & Testimonial & $\$ 30.000$ \\
\hline \multirow{2}{*}{ Notificación sentencia definitiva } & Demandante & $\$ 20.000$ \\
\hline & Demandado & $\$ 20.000$ \\
\hline \multirow{2}{*}{ Apelación sentencia definitiva } & Suspensión vista de la causa & $\$ 20.000$ \\
\hline & Recusación abogado integrante & $\$ 5.000$ \\
\hline \multirow{2}{*}{ Casación } & Suspensión vista de la causa & $\$ 20.000$ \\
\hline & Recusación abogado integrante & $\$ 6.000$ \\
\hline \multicolumn{3}{|c|}{ Compulsas } \\
\hline \multicolumn{3}{|c|}{ Inscripción medida precautoria } \\
\hline \multicolumn{2}{|c|}{ Trámites asociados a la ejecución (embargos, remates, retiro especies, etc.) } & \\
\hline \multicolumn{2}{|c|}{ Peritajes } & \\
\hline \multicolumn{2}{|c|}{ Solicitud de declaración de quiebra } & \\
\hline
\end{tabular}

\footnotetext{
${ }^{16}$ Cifras aproximadas del año 2013. Fuente: Ministerio de Justicia [2013]: “Tasas Judiciales..., p. 17.
} 
El procedimiento de mediación, por contraste, evita el despliegue de todo el aparataje judicial estatal para la solución de un conflicto patrimonial, circunstancia que redunda necesariamente en el menor costo relativo de la solución mediada, para las partes y para el propio Estado. A ello se suma, además, el beneficio económico que trae consigo la solución rápida de las controversias en este ámbito, elemento este que, en el contexto judicial estatal, constituye precisamente uno de los principales desincentivos a la hora de recurrir a la solución heterocompositiva de asuntos con cuantías relativamente menores.

En este punto, aunque advirtiendo por cierto la distinta naturaleza de los intereses y derechos tutelados, resulta pertinente mencionar que el sistema de mediación contemplado en la Ley de Tribunales de Familia, $N^{\circ} 19.968$, establece como regla general la gratuidad del servicio para la mediación de alimentos, cuidado personal y relación directa y regular (siempre y cuando se cumplan determinadas condiciones), circunscribiendo el servicio de mediación pagada al sistema de mediación familiar licitada. Pues bien, y como se dirá más adelante, un sistema de mediación de asuntos comerciales y civiles patrimoniales requiere igualmente -mutatis mutandi-de un compromiso real del Estado, que la haga económicamente atractiva para las partes y jurídicamente eficiente en cuanto mecanismo alternativo de solución de sus conflictos; y todo, claro está, sin perjuicio de la intervención de agentes y centros privados de mediación, al que las partes puedan optar libremente asumiendo los costos involucrados ${ }^{17}$.

Por último, a la baja cuantía de los asuntos y al costo de litigar se suman otros factores que llevan a concluir, también, el pro de la mediación. Es lo que ocurre, por ejemplo, con la lentitud del aparato jurisdiccional estatal en general, inconciliable con la dinámica que impone y requiere el tráfico mercantil; la eventual desconfianza en la justicia estatal y en el arbitraje como sistema alternativo; los costos adicionales asociados al procedimiento arbitral; o, simplemente, la renuencia ante un camino heterocompositivo, judicial o arbitral, que llevará en la mayoría de los casos a un quiebre indeseado en la relación comercial con la contraparte en conflicto. Todos estos elementos, en fin, se traducen en que una gran cantidad de asuntos quedan sin solución, al no existir un incentivo adecuado y económicamente razonable para llegar a ella. La mediación, entonces, viene a llenar un importante vacío en este entorno material, al que ni la Administración de Justicia ni el mecanismo arbitral pueden llegar. Se trata, en concreto, de aquellos conflictos empresariales que por falta de recursos o incentivos económicos, de tiempo, de confianza o de expectativas en los resultados esperables, nunca llegan a los cauces heterocompositivos, traduciéndose por lo mismo en costos irrecuperables para las empresas involucradas y, en términos agregados, para la economía en su totalidad.

${ }^{17}$ Véase en este sentido, a modo ejemplar, las tarifas vigentes del Centro de Arbitraje y Mediación de la Cámara de Comercio de Santiago, disponibles en http://www.camsantiago.cl/tarifas/mediacion.html 


\section{Las cifras que respaldan la mediación comercial en el derecho comunitario europeo}

Muy ilustrativos resultan en este punto los estudios realizados en el ámbito comunitario europeo durante los últimos tres años, que sirvieron además como soporte empírico de este creciente fenómeno de regulación positiva de la mediación de los conflictos del orden civil y comercial. Dichas investigaciones, en efecto, han demostrado que la mediación en esta área constituye un imperativo no solo en el caso de los conflictos transfronterizos, sino también, como se acaba de señalar, cuando se trata de conflictos locales.

Especialmente descriptivo es en este punto el estudio realizado por el "ADR Center", en colaboración con la "European Company Lawyers Association" (ECLA) y la "European Association of Craft, Small and Medium-Sized Enterprises" (UEAPME), encargado por la Comisión Europea en el marco del Proyecto denominado "The Cost of Non ADR - Surveying and Showing the Actual Costs of Intra-Community Commercial Litigation" 18 . El estudio fue realizado a abogados, empresas y Centros de ADR de 26 países miembros, excluido Dinamarca, y si bien muestra el impacto económico que tiene para las empresas la decisión de no someterse a mecanismos alternativos de solución de conflictos en el ámbito transfronterizo, resulta plenamente extrapolable al ámbito de los conflictos empresariales internos y a los costos que ello representa para las empresas. Precisamente, el estudio aspira a que sus resultados motiven a los responsables de formular las políticas y las regulaciones internas de cada país, para que apliquen la Directiva No 2008/52/CE de 21 de mayo, del Parlamento Europeo y del Consejo, Sobre ciertos aspectos de la mediación en asuntos civiles y mercantiles (vid. infra), no solo a los asuntos transnacionales, sino también a nivel nacional.

La mediación -concluye este informe- "ahorra dinero", pero las empresas y sus asesores legales aún no son conscientes de las particularidades y ventajas de la misma, por los costos en dinero y en tiempo que evita para ambos ${ }^{19}$. Así, el estudio demostró que dos de cada cinco de los abogados de empresa encuestados $(39,3 \%)$, y siete de cada diez empresas $(66,6 \%)$, señalaron destinar un tiempo significativo de su actividad a juicios y alegatos, respectivamente. Por su parte, más de dos tercios de esas empresas informaron destinar una parte considerable de su presupuesto a gastos administrativos anuales, relacionados con los costos legales y judiciales de estos juicios, y más de cuatro quintas partes de sus abogados señalaron que sus respectivos clientes incurrían en gastos también considerables. La mayoría de las empresas, además, estimó que no vale la pena recurrir a un litigio para solucionar conflictos cuya cuantía sea inferior a 50.000 euros, mientras que los abogados encuestados estimaron que ese piso variaba entre los 10.000 a 50.000 euros.

18 Versión en inglés disponible en http://www.adrcenter.com/jamsinternational/civil-justice/ Survey_Data_Report.pdf. Número de referencia: JLS/CJ/2007-1/18 - 30-CE-022337900-43, p. 5.

${ }^{19}$ Ibid., pp. 23-25. 
A todo lo anterior, en fin, se suma el desconocimiento y la falta de confianza de las empresas en cuanto a los índices de éxito que se logran en los procedimientos de mediación, los que según sus estimaciones no superarían el $50 \%$ de los casos. Tal circunstancia, como es evidente, refleja la poca información que manejan las empresas en este sentido y explica, consecuencialmente, el desincentivo que existe en cuanto a recurrir a dicho mecanismo. Los abogados de las mismas empresas, en cambio, consideraron que al menos el $80 \%$ de los casos que se someten a mediación terminan con un buen resultado, con una duración media de 40 días y sesiones de aproximadamente 8 horas cada una, lo que se vio confirmado por el hecho de que 3,5 de cada 5 abogados estimó que una reunión con sus clientes, para evaluar la incorporación de una cláusula de mediación obligatoria en sus respectivos contratos, tenía un valor "Considerable" o, derechamente, "Mucho" valor $^{20}$, en el entendido que el mediador sea una persona debidamente capacitada en relación con las materias involucradas en dichos contratos.

Por otra parte, y como se muestra en un reporte de abril de 2012, solicitado por la Dirección General de Justicia de la Comisión Europea ${ }^{21}$, existe un importante segmento de conflictos empresariales que simplemente no se resuelven, pues las partes no promueven ningún mecanismo para ello ni realizan ninguna gestión en ese sentido. Diversas fueron las razones detectadas y que explican este fenómeno, dependiendo de si se trata de tribunales estatales o de mecanismos alternativos de solución de controversias (ADR):

a) En el caso de los órganos jurisdiccionales estatales, el $45 \%$ de las empresas consultadas consideró que el costo de litigar era demasiado alto en relación con la cuantía en disputa; $27 \%$ dijo además que sería un camino demasiado largo y por tal razón inviable; otro $27 \%$ señaló que no tenía mayores expectativas ni interés en judicializar el asunto; y $25 \%$ prefirió no arruinar su relación de negocios con la contraparte ${ }^{22}$.

b) En cuanto a los ADR, se concluyó que la falta de información acerca de estos mecanismos es la principal razón por la que las empresas optan por no utilizarlos. En concreto, y tratándose de la mediación, el 20\% señaló que ni siquiera tenía

${ }^{20}$ Ibíd., p. 27-29.

${ }^{21}$ Reporte Flash Eurobarometer 347: Business-to-Business Alternative Dispute Resolution in the EU, realizado por TNS Político Social a petición de la Dirección General de Justicia de la Comisión Europea, marzo-abril de 2012. Disponible en: http://digitalcommons.ilr.cornell.edu/cgi/viewcontent.cgi? article=1230\&context=intl. Consultado el 12 de junio de 2014.

22 Para las empresas de 22 países europeos, el costo del procedimiento versus la cantidad de dinero involucrada en el conflicto fue la principal razón para no ir a los tribunales. Las empresas de Finlandia (59\%), los Países Bajos (57\%) y Portugal (56\%) fueron las más susceptibles en este sentido, mientras que las empresas en Eslovaquia (52\%), Portugal (46\%), Letonia (43\%) y Rumania (40\%) sostuvieron que el procedimiento ante los tribunales estatales es demasiado largo. La opinión de que no hay nada que obtener de un procedimiento judicial, por último, es más común en Portugal (45\%) y Eslovaquia (38\%), mientras que las empresas griegas (41\%), belgas (40\%) y austríacas (37\%) optaron por arruinar la relación comercial con la otra empresa (Ibíd., p. 31). 
conocimiento de su existencia y el $8 \%$ manifestó que no sabía cómo empezar el procedimiento. En el arbitraje la situación es similar, pues los porcentajes indicados son del $19 \%$ y del $7 \%$, respectivamente. En total, cerca de una cuarta parte de las empresas mencionadas señaló al menos una de estas dos razones para no usar un ADR (24\% para el arbitraje y $25 \%$ para la mediación) ${ }^{23}$.

Resulta evidente, entonces, que la situación descrita genera una dinámica negativa en términos de eficiencia económica y de competitividad, cuyos efectos y alcances a futuro son insospechados. Solo por vía de ejemplo, y volviendo al estudio estadístico antes mencionado, en el ámbito europeo el 38\% de las empresas manifestó haber tenido un conflicto con otra en los últimos tres años, con un monto o cuantía media en disputa - calculado con base en el último problema que tuvo cada empresa- de 28.300 euros en el caso de las controversias internas, y de 44.300 euros para los asuntos fronterizos. En las empresas medianas, esos montos fueron de 47.100 euros y de 106.900 euros, respectivamente; mientras que en las microempresas el monto medio fue de 20.100 euros y de 25.700 euros, respectivamente. De estos conflictos, en fin, el 38,4\% de los ocurridos en el ámbito interno quedó sin solución, mientras que en los transfronterizos el porcentaje fue del $35,8 \%{ }^{24}$.

Todas estas razones, en fin, con más o menos matices, explican y justifican la clara tendencia del derecho comparado en cuanto a incorporar la mediación comercial en las legislaciones internas, incluso como requisito previo e indispensable de acceso a la jurisdicción. Ejemplo de ello -sin perjuicio de los ya mencionados- son los casos de China (aun cuando el término "mediación" no encuentra allí una traducción propia) ${ }^{25}$, Hong Kong ${ }^{26}$

\footnotetext{
23 Ibid., p. 30.
}

${ }^{24}$ Ibid., p. 75.

${ }^{25}$ Cfr. Pissler, B., "Mediation in China", en Hopt y Steffek (eds.), Mediation, Mohr Siebeck, Tübingen, 2007 , p. 607. La legislación china contempla una variada gama de procedimientos de mediación: mediación del pueblo, contemplada en la People's Mediation Act del año 2010; la court-annexed mediation; mediación administrativa; mediación institucional; la mediación industrial o industry-based mediation; y la denominada "gran mediación".

${ }^{26}$ La reforma a la justicia Civil del 2009 estableció varias prioridades de cara a la modernización y eficacia del sistema judicial, entre los que se cuenta el favorecimiento de los sistemas alternativos de solución de conflictos. En tal sentido, el Poder Judicial de ese país dictó la denominada "Orden de Práctica de Mediación 31" (Practice Direction on Mediation o "PD 31"), en vigencia a partir del 1 de enero del 2010, en donde se faculta a los jueces para que, en ejercicio de sus competencias y en casos civiles y comerciales apropiados, deriven a las partes a la mediación previa de sus conflictos, lo que deberá ser acreditado mediante el respectivo Certificado de Mediación. Más recientemente, en junio de 2012 el Concejo Legislativo de Hong Kong aprobó la "Ordenanza de Mediación” (Mediation Ordinance), orientada siempre a favorecer este mecanismo y a asegurar la confidencialidad del mismo. Véase Shahla F. A. y Koo A. K. C., "Mediation in Hong Kong SAR", en Mediation in Asia-Pacific: A Practical Guide to Mediation and Its Impact on Legal Systems, Wolters Kluwer Law \& Business and CCH, Hong Kong, 2011. 
e Indonesia ${ }^{27}$, entre muchos otros; y en el ámbito latinoamericano los casos de Colombia ${ }^{28}$, Perú $^{29}$, Ecuador ${ }^{30}$ y Argentina ${ }^{31}$, por nombrar también algunos.

\section{Algunos antecedentes relativos a la mediación de asuntos COMERCIALES EN EL DERECHO COMPARADO RECIENTE}

Como se acaba de señalar, en la actualidad el auge de la mediación comercial es notorio en el derecho comparado, con marcada presencia en el Derecho comunitario europeo más reciente y en países del cono sur de América ${ }^{32}$. Nos centraremos por ahora en el análisis del primero, en el entendido que se trata de experiencias surgidas de realidades y necesidades perfectamente extrapolables al ámbito empresarial interno e internacional de Chile, y de fenómenos también asimilables de creciente litigiosidad.

${ }^{27}$ En Indonesia la mediación comercial está regulada en el artículo 6(3) de la Arbitration Act de 2010. Junto a ella, la Suprema Corte de ese país ha dictado diversas regulaciones sobre la materia, denominadas "Reglas de la Corte Suprema" (Peraturan Mabkaman Agung). La última de ellas, sobre Court-Annexed Mediation Procedure (en vigor desde el 31 de julio de ese año), establece la mediación ante tribunales religiosos y civiles; y en este último caso como mecanismo que debe ser ejecutado en todos los niveles del procedimiento, incluida la sede de casación (vid. Imanjuntak, M.; Suroto, V.; Nurhayati, R., Capítulo “Indonesia”, en Esplugues Mota, Carlos y Barona Vilar, Silvia (eds.), Global Perspectives on ADR, Intersentia, Cambridge, 2014, pp. 213-215.

${ }^{28}$ La Ley $N^{\circ}$ 640, de 5 de enero de 2001, instituyó la Conciliación Prejudicial Obligatoria en los procesos civiles, comerciales y contencioso-administrativos.

${ }^{29}$ Perú reguló especialmente la mediación mediante la Ley No 26.876, sobre "Conciliación Extrajudicial”. Los artículos 6 y 9 de la ley la establecen también en forma obligatoria y previa, como requisito de procesabilidad, en todos aquellos conflictos sobre "derechos disponibles de las partes".

${ }^{30}$ La "Ley de Arbitraje y Mediación” data de 1997, No RO/145 de 4 de septiembre. El art. 46 letra c) de la misma establece que la mediación procederá Cuando el Juez ordinario disponga en cualquier estado de la causa, de oficio o a petición de parte, que se realice una audiencia de mediación ante un centro de mediación, siempre que las partes lo acepten.

${ }^{31}$ La Ley No 26.589, de 15 de abril de 2010 y promulgada el 3 de mayo del mismo año, sobre Mediación y Conciliación, establece también la mediación como requisito previo obligatorio, indispensable para el inicio de procesos judiciales. Según el art. 4 de la ley, Quedan comprendidas dentro del procedimiento de mediación prejudicial obligatoria todo tipo de controversias, excepto las previstas en el artículo $5^{\circ}(. .$.$) , disposición esta que excluye$ la obligatoriedad en los siguientes casos: a) Acciones penales; b) Acciones de separación personal y divorcio, nulidad de matrimonio, filiación, patria potestad y adopción, con excepción de las cuestiones patrimoniales derivadas de estas. El juez deberá dividir los procesos, derivando la parte patrimonial al mediador; c) Causas en que el Estado nacional, las provincias, los municipios o la Ciudad Autónoma de Buenos Aires o sus entidades descentralizadas sean parte, salvo en el caso que medie autorización expresa y no se trate de ninguno de los supuestos a que se refiere el artículo 841 del Código Civil; d) Procesos de inbabilitación, de declaración de incapacidad y de rehabilitación; e) Amparos, habeas corpus, habeas data e interdictos; f) Medidas cautelares; g) Diligencias preliminares y prueba anticipada; b) Juicios sucesorios; i) Concursos preventivos y quiebras; j) Convocatoria a asamblea de copropietarios prevista por el artículo 10 de la Ley $N^{0} 13.512$; k) Conflictos de competencia de la justicia del trabajo; l) Procesos voluntarios.

${ }^{32}$ Véanse las notas 27, 28, 29 y 30 anteriores. 


\section{La experiencia europea durante los últimos años}

A partir de la Directiva 2008/52/CE, del Parlamento Europeo y del Consejo, de 21 de mayo de 2008, Sobre ciertos aspectos de la mediación en asuntos civiles y mercantiles ${ }^{33}$, precedida por el denominado "Libro Verde" de la Comisión Europea, del 2002 ${ }^{34}$, y por la Propuesta de Directiva sobre mediación del 2004, los países de la Unión Europea han debido incorporar a sus legislaciones internas un elenco normativo mínimo para fomentar la mediación en los litigios transfronterizos de carácter civil y mercantil.

En esa tarea, sin embargo, muchos de esos países han ido más allá de lo que impone la señalada Directiva, incorporando también la mediación civil y mercantil como alternativa complementaria de solución de los conflictos internos, recogiendo así los lineamientos que planteara en su momento la Propuesta de Directiva recién mencionada y el interés generalizado, tanto de empresas como de abogados, de contar con una legislación interna que incluya la mediación comercial como previa y obligatoria ${ }^{35}$.

\subsection{El caso de España y la mediación voluntaria}

Desde la dictación de la Ley de Enjuiciamiento Civil, en 1881, hasta su reforma de 31 de agosto de 1984, la mediación en España - entonces llamada “conciliación”- fue

\footnotetext{
${ }^{33}$ Más recientemente, el legislador europeo adoptó una nueva Directiva en materia de ADR No 11/2013 de 18 de junio, aunque reservada esta vez a las controversias entre empresas y consumidores. A ella se suma el también reciente Reglamento UE No 514/2013, de 21 de mayo, sobre Online Dispute Resolution, siempre a propósito de los conflictos entre proveedores y consumidores y, concretamente, a propósito de los contratos de compraventa y de prestación de servicios celebrados también online.

${ }^{34}$ Se trata del Libro Verde, sobre las modalidades alternativas de solución de conflictos en el ámbito del derecho civil y mercantil, de 19 de abril de 2002, publicado por la CE el 19 de abril de 2002, que sirvió a su vez de antecedente a la Propuesta de Directiva sobre mediación presentada por la CE el 22 de octubre de 2004. Ambas iniciativas se orientan a promover las modalidades alternativas de solución de conflictos en el ámbito del derecho civil y mercantil, y a proponer un marco regulatorio común. Según la Comisión, en efecto, "las ADR representan una prioridad política - confirmada en varias ocasiones- para las instituciones de la Unión Europea, a las que incumbe promover estas modalidades alternativas, procurar el mejor entorno posible para su desarrollo y esforzarse por garantizar su calidad. Se ha hecho especial hincapié en esta prioridad política en el ámbito de la sociedad de la información en el que se reconoce el papel de los nuevos servicios en línea de solución de conflictos (ODR por Online Dispute Resolution) en materia de solución de litigios transfronterizos a través de Internet" (Libro Verde, 2002, p. 5. Disponible en http://www.icam.es/docs/ ficheros/201202170001_6_3.pdf. Consultado el 12 de junio de 2014).

35 Según el Informe mencionado supra, sobre los costos de no negociar en los asuntos comerciales, casi el $80 \%$ de los abogados encuestados dijeron estar a favor de la promulgación de una ley de mediación comercial previa y obligatoria, mientras que más del $50 \%$ de las empresas se manifestaron en igual sentido (The Cost of Non ADR..., p. 36). A modo de conclusión, el Informe señala en este punto: "En un esfuerzo evidente por mejorar los negocios y las asociaciones dentro de la comunidad, las empresas y los abogados de la UE abrumadoramente apoyan la promulgación de una ley nacional que requiera mediaciones previas al juicio. Reforzada por hallazgos más importantes de este estudio, elegir la mediación sobre el litigio probablemente ampliaría la cantidad, variedad, y la eficiencia de las transacciones comerciales internacionales intracomunitarios y el desarrollo" (Traducción libre del autor).
} 
obligatoria $^{36}$, elevada incluso al rango de presupuesto procesal por influjo de la Constitución de Cádiz de 1812, que dedicaba tres artículos a la conciliación obligatoria previa ${ }^{37}$. Sin embargo, y debido a la falta de una regulación complementaria básica que incentivara su aplicación y reforzara sus efectos, con el correr del tiempo aquella "había quedado convertida en un rito carente de contenido, y sin eficacia pacificadora de contiendas ni en la vida social ni en el mundo empresarial" 38.

Décadas más tarde, la ley española $\mathrm{N}^{\circ}$ 5/2012, de 6 de julio, sobre Mediación en asuntos civiles y mercantiles, incorporó al Derecho español la Directiva 2008/52/CE, mencionada supra. En su regulación, sin embargo, la ley superó con mucho los contenidos y aspectos que la normativa comunitaria le mandaba transponer, orientados básicamente a incentivar el uso de la mediación en los conflictos transfronterizos, extendiéndose en general a todos los conflictos de derecho privado que tengan lugar en España con excepción, entre otros, de los asuntos de consumo ${ }^{39}$.

En su Exposición de Motivos, la ley le asigna a la mediación el carácter de vehículo privilegiado para descomprimir el quehacer de los tribunales estatales, en el entendido que aquella contribuye a concebir a los tribunales de justicia en este sector del ordenamiento jurídico como un último remedio, en caso de que no sea posible componer la situación por la mera voluntad de las partes, y puede ser un hábil coadyuvante para la reducción de la carga de trabajo de aquéllos. En sus apartados II y III, a su vez, la misma Exposición fija los grandes lineamientos y fines de la Ley, señalando como tales (a) la desjudicialización de los asuntos civiles y mercantiles, para reducir la carga de trabajo de los tribunales; (b) la flexibilidad del contenido del acuerdo resultante de la mediación, con miras al logro de soluciones en las que no se aplique la ecuación "vencedor-vencido", propia del proceso heterocompositivo ${ }^{40}$; y (c) la primacía del principio dispositivo y de la autonomía de la voluntad de las partes, por sobre el protagonismo de la ley.

36 Véase el art. 460 de la LEC, en su texto original.

${ }^{37}$ Artículo 282: El alcalde de cada pueblo ejercerá en él el oficio de conciliador, y el que tenga que demandar por negocios civiles o por injurias, deberá presentarse a él con este objeto.

Artículo 283: El alcalde con dos hombres buenos, nombrados uno por cada parte, oirá al demandante y al demandado, se enterará de las razones en que respectivamente apoyen su intención, y tomará, oído el dictamen de los dos asociados, la providencia que le parezca propia para el fin de terminar el litigio sin más progreso, como se terminará en efecto, si las partes se aquietan con esta decisión extrajudicial.

Artículo 284: Sin hacer constar que se ha intentado el medio de conciliación, no se establecerá pleito ninguno.

${ }^{38}$ Martí Mingarro, L.: “La mediación civil y mercantil en la nueva ley 5/2012, de 6 de julio", en Revista Jurídica de Castilla y León, No 29, enero de 2013, p. 13.

39 La mediación de consumo está especialmente contemplada en el RDL 231/2008, de 15 febrero, que regula el Sistema Arbitral de Consumo. Según el art. 6, letra f), es función de Las Juntas Arbitrales de Consumo Asegurar el recurso a la mediación previa al conocimiento del conflicto por los órganos arbitrales (...). El art. 38.1, a su vez, establece que Cuando no existan causas de inadmisión de la solicitud de arbitraje se intentará mediar para que las partes alcancen un acuerdo que ponga fin al conflicto, salvo oposición expresa de cualquiera de las partes o cuando conste que la mediación ha sido intentada sin efecto, creando así un sistema intermedio de mediación previa aunque no obligatoria.

${ }^{40}$ Vid. Trigo Sierra, E. y Moya Fernández, A.: "La mediación civil y mercantil en España y en el derecho

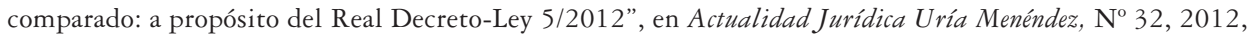


Así, y tomando como base las disposiciones de la Ley Modelo UNCITRAL sobre Conciliación Comercial Internacional, de 24 de junio de $2002^{41}$, la ley española le asigna a la mediación mercantil una función de primera línea para la solución de conflictos, sustentada en la autonomía de la voluntad ${ }^{42}$ y en el principio de igualdad de las partes y de equilibrio y respecto de sus opiniones (art. 8); en el de neutralidad e imparcialidad del mediador (art. 9); y en el principio base de la confidencialidad, por el que se prohíbe al mediador y a las partes revelar la información obtenida con ocasión del procedimiento y se releva adicionalmente, a las demás personas que hayan intervenido en el mismo, del deber de declarar luego en juicio o en un arbitraje (art. 9) ${ }^{43}$.

A todo lo anterior, por último, se suman dos factores igualmente indispensables para el buen funcionamiento del engranaje en su conjunto: (a) la necesaria suspensión de los plazos de prescripción y caducidad, por todo el tiempo que dure el procedimiento de mediación, lo que constituye otro pilar fundamental para el funcionamiento del sistema, orientado esta vez a eliminar los posibles desincentivos y a evitar los eventuales abusos por efectos jurídicos no deseados (art. 4); y (b) la ejecutividad que se le asigna al título en que consta el acuerdo de mediación, dependiendo si este se logró antes o durante el proceso judicial o arbitral, y dentro o fuera del país (art. 25 y ss.).

p. 103. Así lo ha dicho reiteradamente también el TS español. Por todas: No es baldío tener presente que en este, como en otros tantos conflictos, tanto familiares, como civiles o mercantiles en general (así, Directiva 2008/52 / CE del Parlamento europeo y del Consejo de 21 de mayo de 2008 (LCEur 2008, 803), sobre ciertos aspectos de la mediación en asuntos civiles y mercantiles), podría una mediación llegar a soluciones menos traumáticas que el proceso y el acuerdo a que se podría llegar siempre sería menos duro que la resolución judicial que se apoya exclusivamente en la aplicación de la norma jurídica (STS, de 3 de julio de 2009. RJ 2009\5491).

${ }^{41}$ Como señaló la Asamblea General al dar su aprobación a la Ley Modelo del 2002, los "métodos de solución de controversias, a los que se alude con expresiones tales como conciliación y mediación y términos similares, se usan cada vez más en la práctica mercantil nacional e internacional en sustitución de los litigios judiciales". Tal mecanismo -continúa la Asamblea- "produce beneficios importantes, pues reduce los casos en que una controversia lleva a la terminación de una relación mercantil, facilita la administración de las transacciones internacionales por las partes comerciales y da lugar a economías en la administración de justicia por los Estados" (Disponible en http://www.uncitral.org/pdf/spanish/texts/arbitration/mlconc/03-90956_Ebook.pdf. Consultada el 17 de junio de 2014).

42 Nótese que esta voluntariedad no era tan amplia en el Proyecto y Anteproyecto de Ley. En el primero, la norma señalaba que La mediación es voluntaria, sin perjuicio de la obligatoriedad de su inicio cuando lo prevea la legislación procesal, mientras que el segundo -el Anteproyecto- establecía que El sometimiento a mediación es voluntario, sin perjuicio de la obligatoriedad de su inicio cuando lo prevea esta ley o la legislación procesal.

${ }^{43}$ Según el art. 9.2, La confidencialidad de la mediación y de su contenido impide que los mediadores o las personas que participen en el procedimiento de mediación estén obligados a declarar o aportar documentación en un procedimiento judicial o en un arbitraje sobre la información y documentación derivada de un procedimiento de mediación o relacionada con el mismo, excepto:

a) Cuando las partes de manera expresa y por escrito les dispensen del deber de confidencialidad.

b) Cuando, mediante resolución judicial motivada, sea solicitada por los jueces del orden jurisdiccional penal. 


\subsection{Algunos sistemas de mediación obligatoria}

Otros países europeos, como Italia, Alemania e Inglaterra, han optado por incorporar un sistema de mediación o de conciliación previa obligatoria de asuntos civiles y comerciales, aunque con mayor o menor intensidad.

\subsubsection{El caso italiano}

A partir de los años 90 del siglo pasado, y concretamente de la Ley $\mathrm{N}^{\circ}$ 580/1993, sobre la reordenación de las cámaras de comercio, el derecho italiano ha experimentado un notorio avance en materia de mediación, plasmado finalmente en el Decreto Legislativo $\mathrm{N}^{\mathrm{o}}$ 28/2010, de 5 de marzo, que abandonó la lógica de la intervención sectorial del legislador en esta materia para implantar una disciplina general de la mediación en asuntos civiles y comerciales. Así, el artículo $5^{\circ}$ del DL consagra en Italia la mediación previa como un requisito de procesabilidad de las acciones relativas a controversias en materia de copropiedad, derechos reales, división, sucesión hereditaria, pactos de familia, arrendamiento, comodato, alquiler de ascienda, responsabilidad por el daño causado por la circulación de vehículos y embarcaciones, responsabilidad médica y la que proviene de difamaciones por medios escritos o por cualquier otro medio de publicidad, y las derivadas de contratos de seguro, bancarios y financieros; sin perjuicio de la facultad del juez para proponer la mediación durante el curso del juicio. Asimismo, y a diferencia del sistema norteamericano y el de la mayoría de los países europeos, el modelo italiano se basa principalmente en los organismos o instituciones públicas o privadas de mediación, más que en los mediadores individualmente considerados, las que si bien están sometidas a las reglas del mercado y de la libre competencia, son fiscalizadas por el Estado mediante la inscripción previa en un registro que lleva el Ministerio de Justicia ${ }^{44}$. Del mismo modo, el DL se encarga especialmente de velar por la calidad en la formación de los mediadores que prestan servicios en dichas instituciones, la que es controlada también por el Estado mediante la inscripción previa obligatoria de los organismos de formación, ante el mismo Ministerio.

\subsubsection{El caso de Alemania: conciliación obligatoria previa para asuntos de poca} entidad

La conciliación, aunque conceptualmente distinta de la mediación como mecanismo de autocomposición ${ }^{45}$ constituye un instrumento de general aplicación en el derecho

${ }^{44}$ Vid. Besso, Ch.: "La Mediazione Italiana: Definizioni e Tipologie", en Revista Eletrônica de Direito Processual, Rio de Janeiro, Año 4, Vol. VI, 2012, pp. 248-269. Disponible en http://www.arcos.org.br/ periodicos/revista-eletronica-de-direito-processual/volume-vi/la-mediazione-italiana-definizioni-etipologie\#topo Consultado el 16 de junio de 2015.

$45 \mathrm{La}$ conciliación admite dos acepciones, una amplia y otra técnica o procesal. En la primera, por conciliación se entiende indistintamente todo acuerdo o avenimiento entre dos personas que sostienen 
alemán. El art. 278.1 de la Ley de Enjuiciamiento Civil, en efecto, exige que el tribunal promueva e intente en todo momento un acuerdo directo entre las partes. Todavía más, según el apartado $2^{\circ}$ de la misma disposición, incorporado en el 2002, el juez está obligado a proponer un procedimiento de conciliación como requisito previo para iniciar el procedimiento contencioso, en la medida que ello "no resulte inútil", lo que se traduce en un sistema de obligatoriedad previa intermedia o atenuada, que radica en último término en el criterio del tribunal.

Sin perjuicio de lo anterior, el artículo 15 de la Ley de Introducción a la Ley alemana de Enjuiciamiento Civil (Gesetz betreffend die Einfübrung del Zivilprozesordnung), de 1999, faculta a los Estados Federales para que incorporen la mediación obligatoria previa para asuntos patrimoniales de poca cuantía (hasta 750 Euros), la que en todo caso debe llevarse a cabo ante un organismo de conciliación extrajudicial. Esta autorización, recogida por diversos estados, se ha traducido por ejemplo en fórmulas innovadoras como la de Baviera ${ }^{46}$, donde se ha nombrado a los Notarios como organismos encargados de llevar a cabo estos procedimientos ${ }^{47}$.

\subsection{El caso intermedio de Inglaterra y el deber de colaboración}

En la legislación del Reino Unido, por último, la mediación es esencialmente voluntaria y no se encuentra regulada especialmente. Sin embargo, la voluntariedad recién apuntada se desdibuja tan pronto se revisan las normas generales contempladas en el Civil Procedure Rules.

Según el art. 26.4, en efecto, el juez está facultado para derivar a las partes a mediación, antes y durante el procedimiento, y para suspenderlo en este último caso

posturas distintas, lo que se puede lograr por vía judicial o extrajudicial. En su sentido técnico, en cambio, la conciliación supone la existencia de un proceso judicial en curso, que termina precisamente por esta vía anormal cuando la ley así lo permite. Distinto es el caso de la mediación, que no requiere de la intervención del juez ni de la existencia de un litigio, como tampoco de la homologación judicial del acuerdo.

${ }^{46}$ Vid. De la Rosa, F. E. (dir.) y Garrido Carrillo, F. J. (coord.): Mediación y arbitraje de consumo, Tirant lo Blanch, Valencia, 2010, pp. 230 y 231.

${ }^{47}$ La función de los Notarios en Alemania, como gestores de soluciones mediadas y como árbitros, ha tenido un desarrollo generalizado. En virtud del art. $8^{\circ}$, párrafo 3, del Reglamento Notarial alemán (Bundesnotarordnung), en su calidad de titulares de un cargo público los Notarios pueden intervenir como mediadores o árbitros sin necesidad de otra autorización, con miras a neutralizar y solucionar conflictos mediante el asesoramiento y la discusión imparcial. Se trata-dice Geimer-de uno de los campos de actividad "naturales" de los Notarios, que pueden por lo mismo "desempeñar funciones próximas a las judiciales con el fin de descargar la justicia”. En este sentido, el Colegio de Notarios alemán ha dispuesto un Reglamento aplicable a la conciliación mediante Notario, mientras que la Asociación alemana de Notarios ha creado un tribunal de arbitraje institucional denominado "Tribunal de arbitraje y conciliación de los notarios alemanes" (Geimer, R.: "Circulación del documento notarial y sus efectos como título legitimador en el tráfico jurídico", en "XXIII Congreso Internacional del Notariado Latino”, Ponencia de la Delegación Alemana, Atenas, 1 al 7 de octubre de 2001, p. 8.) Ver en http://bundesnotarkammer.de/_downloads/UINL_Kongress/Athen/ GEIMER_ESPANOL.pdf Consultado el 17 de junio de 2015. 
durante un mes. Tal llamado no es obligatorio, por cierto; pero la parte que se rehúsa injustificadamente a someterse a mediación, cuando el juez o la contraparte la sugieren con razonable fundamento, podrá ser sancionada con las costas del juicio ${ }^{48}$.

El tribunal, por tal razón, deberá considerar especialmente la conducta de las partes y los esfuerzos que han realizado para solucionar el conflicto por este medio alternativo, antes y durante el procedimiento. De esta forma, y por poner un ejemplo, si la parte que ha rechazado un llamado previo a mediación gana posteriormente el juicio, el juez podrá sancionarla por la vía de liberar a la parte perdidosa del pago de las costas, lo que constituye una novedosa fórmula para imponer el deber de colaboración y buena fe de las partes en conflicto, pese a lo compleja que esta pueda resultar en su materialización casuística.

En general, el sistema de mediación está entregado aquí al Ministerio de Justicia y a la colaboración del "Consejo de Mediación en Asuntos Civiles", organismo que representa a los prestadores de servicios de mediación civil y mercantil y que se encarga, además, de ofrecer el servicio de acreditación de los mediadores. Los órganos jurisdiccionales, en consecuencia, derivan los asuntos únicamente a los prestadores de servicios de mediación que se encuentran acreditados por el Centro.

Gracias a este sistema, en fin, y según estadísticas del Centre of Efective Dispute Resolution (CEDR), solo en el 2009 fueron resueltos en ese Centro 6.000 asuntos comerciales vía mediación ${ }^{49}$.

\section{El sistema del court annexed mediation}

Para concluir esta breve revisión de mecanismos de mediación en el derecho comparado, resulta de especial interés mencionar el novedoso sistema del court annexed mediation (mediación anexa a la Corte), aplicado en varios estados de los Estados Unidos de Norteamérica y en países de todos los continentes, como Sudáfrica ${ }^{50}$, Puerto Rico ${ }^{51}$,

${ }^{48}$ En este sentido, en el caso McMillan Williams vs. Range, del 2004, la Corte de Apelaciones señaló que si son ambas partes las que se rehúsan a seguir la sugerencia del juez, de someterse a mediación, cada una deberá asumir los costos del juicio, sin que pueda condenarse a ninguna de ellas a soportar las costas (EWCA Civ. 294;[2004] 1 WLR 1858).

${ }^{49}$ Información disponible en www.cedr.com/index.php?location=/news/archive/20100513_347.htm > Consultado el 16 de junio de 2014.

${ }^{50}$ Las reglas sobre Court-Annexed Mediation en Sudáfrica se contienen en el capítulo $2^{\circ}$ de las Magistrates' Courts Rules, y fueron aprobadas por el Ministerio de Justicia y Desarrollo Constitucional para entrar en operación, como plan piloto, el 1 de diciembre de 2014. Para mayor información puede consultarse la web: http://www.justice.gov.za/mediation/mediation.html\#sthash.tM3GaUCG.dpuf

${ }^{51} \mathrm{La}$ Local Civil Rule 83.J establece que todos los asuntos civiles son elegibles para mediación, por decisión discrecional del tribunal, por solicitud de una de las partes o por estipulación de todas ellas. 
Filipinas $^{52}$ y Australia ${ }^{53}$-por nombrar algunos-, lo que evidencia una tendencia global hacia la mediación de asuntos patrimoniales.

En términos generales, en el sistema de court annexed mediation cualquiera de las partes, o el tribunal de oficio, pueden optar por la mediación para resolver el conflicto, antes o durante el juicio. En el primer caso, y formulada la solicitud respectiva, el tribunal la resolverá oyendo a las demás partes, que pueden por cierto oponerse a ella, pero será el juez quien determine finalmente si la mediación es o no el camino indicado para el caso concreto.

La asistencia y participación de las partes y sus abogados a la mediación es generalmente obligatoria, a menos que el tribunal señale lo contrario. En el caso del estado de Mississippi, por poner un ejemplo, el Reglamento de Mediación Anexa a la Corte establece que la ausencia de alguna de las partes, o su falta de participación y

52 A fines de la década de 1990 del siglo pasado, el Tribunal Supremo de Filipinas emitió tres directivas que tendrían un impacto significativo en el desarrollo de la mediación en ese país. La primera fue la enmienda de 1997 al Reglamento de la Corte, con el fin de autorizar a los tribunales para que consideraran la remisión de casos no solo a arbitraje, sino también a otros modos alternativos de resolución de conflictos y entre ellos la mediación. La segunda fue la Directiva de 1999, sobre court annexed mediation o "mediación anexa a la Corte", como prueba piloto en dos ciudades del área metropolitana de Manila, la ciudad de Mandaluyong y Valenzuela City. La tercera fue la adopción en 1999 de un proyecto original de acción para el Poder Judicial, orientado a la formación de los jueces en la mediación y la conciliación durante la etapa previa al juicio. En concreto, el programa de court annexed mediation está destinado a resolver extrajudicialmente los siguientes casos: a) Los asuntos civiles que involucran a miembros de una misma familia, hasta el sexto grado de consanguinidad o afinidad, salvo las que por ley no pueden ser objeto de compromiso; b) Los casos basados en la relación entre acreedor y deudor; c) Las reclamaciones por daños civiles; d) Las controversias entre arrendador y arrendatario; y e) En general, las disputas civiles entre residentes del mismo municipio o ciudad, que puedan ser conocidas por el Lupon Tagapamayapa o "Comité de Pacificación", en conformidad con la Sección 408 del Código de Gobierno Local de 1991 (cada municipio o ciudad cuenta con este tipo de entidad privada, organizada por los propios ciudadanos con el fin de solucionar extrajudicialmente los casos de menor importancia entre los residentes del barangay). Durante los dos primeros meses del plan piloto, el $42 \%$ de los casos llevados a mediación anexa se solucionaron exitosamente, lo que llevó a la Suprema Corte a incrementar el número de mediadores y jueces capacitados en mediación. Con este esquema, entre el 26 de marzo y el 6 de abril de 2001 la Corte envió 1.816 casos a mediación, de estos 1.469 (81\%) terminaron en acuerdos, mientras que solo 347 (19\%) fracasaron (vid. De los Ángeles, E.: Court-Annexed Mediation: The Philippine Experience. Texto en inglés disponible en http://www.aseanlawassociation.org/docs/w4_phil. pdf Consultado el 17 de junio de 2015).

53 En Australia, la mediación tiene un largo historial de reconocimiento legal. Ya en la Supreme Court Act, de 1935, la sección IV, arts. 69 a 72, regula explícitamente la mediación para resolver los conflictos sometidos a la Corte. Por su parte, el sistema de court annexed mediation data de 1983, aunque el programa de mediación anexa del Tribunal Federal de Australia es de 1987, lanzado como plan piloto en Nueva Gales del Sur. Durante la década de 1990, el sistema cobró gran fuerza y se convirtió en un movimiento de general aceptación, al punto que en 1992 el entonces presidente del Tribunal Supremo de la Corte Suprema de Victoria llegó a la conclusión que los retrasos en la Corte Suprema solo podían ser resueltos por una mediación, "haciendo un masivo y poderoso esfuerzo en el uso de la mediación, como vehículo para conseguir la solución de los casos" (vid. NorTh, John [2005]: "Mediación Anexa a la Corte en Australia. Una visión general". Discurso pronunciado el 17 de noviembre en la Malaysian Law Conference. Texto en inglés disponible en http://www.lawcouncil.asn.au/lawcouncil/images/LCA- PDF/speeches/20051117CourtAnnexedM ediationinAustralia.pdf Traducción libre del autor. Consultado el 17 de junio de 2015. 
colaboración en el procedimiento de mediación, podrá ser denunciada por la otra parte a la Corte respectiva, la que podrá sancionar a la parte o a sus abogados con el pago de los gastos razonables incurridos por cualquier incumplimiento a esta regla, incluyendo los honorarios del abogado de la otra parte y los del mediador. Estos últimos, por lo general, son pagados por la parte que solicitó la mediación, salvo acuerdo en contrario; o por ambas, si la decisión fue adoptada de oficio por el tribunal ${ }^{54}$.

Como se ve, en fin, la mediación en este sistema tampoco es enteramente obligatoria, pues depende en principio de la iniciativa de las partes. Puede serlo, sin embargo, cuando la Corte así lo decida, sea de oficio o resolviendo las oposiciones en la audiencia respectiva; pero cualquiera que sea el origen de la mediación, la colaboración y buena fe de las partes, en cuanto a la búsqueda leal de una solución al conflicto, es una obligación concreta cuya infracción queda sujeta a sanción.

\section{LA INTERVENCIÓN DEL ESTADO EN EL SISTEMA DE MEDIACIÓN COMERCIAL}

Avanzado el estudio hasta aquí, podemos concluir que el soporte y el compromiso del Estado constituyen un nutriente indispensable a la hora de avanzar hacia la implementación de un sistema eficiente de mediación de asuntos empresariales, civiles y comerciales, que no puede quedar entregado a la sola iniciativa privada.

En un contexto como el chileno, en donde no existe mayor cultura respecto de la mediación mercantil y sus atributos, la puesta en marcha y el desarrollo de la misma en este ámbito supone algo más que el respaldo gubernamental a iniciativas públicas o privadas de estímulo a la mediación, o el apoyo financiero a programas, centros o actividades orientadas al mismo fin. Mucho más que eso, y como lo señalan también algunos estudios especializados ${ }^{55}$, la experiencia comparada muestra que es altamente improbable encontrar un solo caso en que los intentos por introducir la mediación, solo mediante la promoción y la capacitación, haya sido exitoso. Ambos aspectos son útiles y necesarios sin duda; pero insuficientes en una etapa de lanzamiento que, como tal, no puede quedar entregada únicamente a las reglas del mercado.

\section{Intervención del Estado en su perspectiva normativa}

En primer lugar, nos parece que el Estado legislador debe ofrecer una estructura normativa básica que le asegure a las partes la posibilidad de mediar eficazmente sus conflictos mercantiles; pero no solo como alternativa para evitar un juicio entre ellas,

54 Apartado IV del Reglamento, según texto modificado el 27 de junio de 2002, que reemplazó el plan piloto de mediación adoptado por la Corte Suprema de ese Estado el 20 de junio de 1996, por orden de fecha 12 de junio del mismo año. Disponible en: https://courts.ms.gov/rules/msrulesofcourt/ court_annexed_mediation.pdf

55 "The cost of non ...", pp. 43 y 44. 
sea de forma previa obligatoria o por medio de un pacto de sujeción a mediación que lleve aparejada la declinatoria de competencia, sino también como manera de suspender el juicio que ya se ha iniciado y de disponer por ende de su objeto, si se trata de materias disponibles en derecho. El juez, antes o durante el juicio, debe tener la facultad de invitar o incluso de forzar a las partes -y para determinados asuntos- a someterse a un procedimiento de mediación ante mediadores calificados y debidamente certificados ${ }^{56}$, sea de oficio o a solicitud fundada de alguna de las partes, incluyéndose aquí -como lo han hecho ya algunas legislaciones extranjeras según lo dicho supra- la posibilidad de que el tribunal suspenda el procedimiento contencioso por tiempo prudencial, para intentar precisamente una solución amistosa por vía de mediación.

\section{En cuanto a la idoneidad del sistema y de sus agentes}

Por lo demás, la certificación de idoneidad de los mediadores es también un factor determinante para el éxito de la mediación, al menos en términos estructurales. Por ello, y si bien es cierto que a la luz del art. 19 N 15 de la Constitución Política de 1980 sería inviable exigir en Chile la afiliación previa de los mediadores a una institución certificada de mediación (como ocurre en otros países), lo concreto es que dicho factor no puede quedar entregado tampoco al libre juego del mercado. Lejos de eso, y como lo muestra la experiencia comparada mencionada supra, la idoneidad de los mediadores en particular, y la eficiencia del sistema en general, suponen necesariamente la intervención del Estado en su rol de fiscalizador; tal como ocurre, por lo demás, con la gestión de otras tantas entidades públicas o privadas orientadas a la prestación de un servicio de interés público.

\section{En cuanto a la colaboración de las partes}

Como tercer pilar de la estructura que se plantea, el éxito de cualquier modelo de mediación requiere también de incentivos concretos de cara a la colaboración leal y de buena fe de las partes sometidas a ella. La omisión de este factor, pues, implica claudicar a priori ante la predisposición vernácula de nuestro medio, que por falta de información o por las razones ya dichas, se muestra mayoritariamente renuente ante toda forma de solución alternativa de conflictos.

En virtud del principio de colaboración procesal, el justiciable se encuentra obligado a observar una conducta de cooperación con la función judicial, de cara a la solución de los conflictos, fundado en una concepción solidaria del proceso que entronca, finalmente, con el principio de la buena fe y probidad procesal. Dicho de otra forma, el deber de

56 A la luz del art. $19 \mathrm{~N}^{\mathrm{o}} 15$ de la Constitución Política de 1980, la exigencia de pertenecer a una institución certificada de mediadores, como ocurre en otros sistemas, no resulta viable. Sin embargo, la certificación de idoneidad de los mediadores es un factor determinante para el éxito de la mediación en términos estructurales, lo que supone por tanto la intervención del Estado en su rol de fiscalizador, como ocurre con otras tantas entidades orientadas a la prestación de un servicio de interés público. 
colaboración constituye concretamente una manifestación del principio general de la buena fe en el ámbito del proceso; o como dice Bustamante ${ }^{57}$ : "el conjunto de reglas de conducta, gobernadas por el imperativo ético, a las cuales deben ajustarse todos los sujetos del proceso (...)" que "proscribe la malicia, la mala fe y la deshonestidad como instrumentos inaceptables para ganar los pleitos”. Elocuente resulta en este sentido la experiencia del ya mencionado Centro de Mediación y Arbitraje, de la Cámara de Comercio de Santiago -CAM Santiago-, que entre el 2013 al 2015 ha tenido un ingreso total de 38 mediaciones. De ellas, pues, ninguna se ha traducido en un acuerdo entre las partes -al menos hasta aquí-, lo que se debe en buena medida a la escaza colaboración de las mismas y a la opción preconcebida de sortear en el menor tiempo posible los efectos vinculantes de una cláusula de mediación previa que, más que una oportunidad para solucionar el conflicto, se ve como un obstáculo para recurrir derechamente a la vía arbitral o judicial. El detalle de lo dicho se expresa en las siguientes tablas ${ }^{58}$ :

Estadísticas Mediaciones CAM Santiago años 2013, 2014 y 2015

\begin{tabular}{lc}
\hline Año & No de causas ingresadas $^{\circ}$ \\
\hline 2013 & 16 \\
\hline 2014 & 11 \\
\hline 2015 (al 26 de junio de 2015) & 11 \\
\hline Total & 38 \\
\hline
\end{tabular}

\begin{tabular}{ccccc}
\hline Causales de término & Frustradas & Sin acuerdo & $\begin{array}{c}\text { Archivadas sin } \\
\text { actividad de las partes }\end{array}$ & En tramitación \\
\cline { 1 - 3 } Año & 11 & 2 & 3 & 0 \\
\hline 2013 & 5 & 4 & 1 & 1 \\
\hline 2014 & 3 & 2 & 0 & 6 \\
\hline
\end{tabular}

Conscientes de este fenómeno, por cierto generalizado, las fórmulas que se han intentado en los ordenamientos comparados son diversas. De todas ellas, sin embargo,

57 Bustamante Rúa, M. (2010): "Principios del Derecho procesal”, en Derecho procesal contemporáneo (Medellín, Universidad de Medellín), p. 98. Véase también Palomo Vélez, D. (2013): "Las cargas probatorias dinámicas: ¿es indispensable darse toda esta vuelta?”, en Revista Ius et Praxis (año 19, No 2), p 449; Cappelletti, M. (1969): "Le grandi tendenze evolutive del proceso civile nel diritto comparato", en Processo e idelogie, (Bolonia, Il Moulino), p. 169.

${ }^{58}$ Fuente: CAM Santiago, 24 de junio de 2015. 
se puede observar una vertiente que se reitera en algunos sistemas y, principalmente, en el modelo de court annexed mediation. En este, como se dijo, se contempla un mecanismo de eficiencia ex ante o de persuasión negativa basado en el sistema de costas y, en algunos casos, en el pago adicional de todos los gastos y honorarios asociados al procedimiento de mediación, según previa determinación jurisdiccional, lo que se ha traducido en un cambio sustancial en la conducta de las partes.

No nos extenderemos mayormente en este aspecto por ahora, pues supera el ámbito material del que nos hemos propuesto como objeto de estudio. Sin embargo, no debe olvidarse que, de conformidad con el artículo 94 del Código de Ética Profesional del Colegio de Abogados de Chile AG, del 2011, la promoción de una solución alternativa a los conflictos constituye también un deber ético de los abogados que intervengan profesionalmente en ellos, y no solo una opción más a la que puedan echar mano eventual y discrecionalmente. Según la norma mencionada, que trata precisamente de la Resolución alternativa de conflictos, El abogado debe hacer los mejores esfuerzos para evitar o poner término a un conflicto judicial mediante los mecanismos legales, siempre y cuando favorezcan una justa transacción o resultado a favor de su cliente, lo que supone una colaboración también leal y de buena fe. Como apunta Martí, en fin, "Los abogados hemos tenido y tenemos desde tiempo inmemorial la obligación de conducir nuestro desempeño profesional por el camino de la concordia. Probablemente no todos, o no siempre, cumplimos con esa obligación deontológica; y en todo caso es más frecuente todavía el cliente más o menos comprometido, acaso indómito, que espera que lo que él entiende como su verdad se la diga un juez. Juegan en ello estrategias, intereses, compromisos y también, por qué no decirlo, un cierto sentido mítico de la justicia" ${ }^{59}$.

\section{En cuanto a la ejecución del acuerdo de mediación}

Finalmente, uno de los principales obstáculos para el desarrollo de la mediación, a nivel interno e internacional, radica en la falta de regulación de algún mecanismo de ejecución del acuerdo resultante de la misma, que dé certeza a las partes en cuanto a su efectivo cumplimiento como ocurre con el arbitraje ${ }^{60}$.

El acuerdo de mediación, como contrato que es, constituye una ley para las partes (art. 1545 del Cod. Civil) y, como tal, faculta a la parte que quiere hacerlo cumplir para exigir precisamente ese cumplimiento o para demandar su resolución, y en ambos casos con indemnización de perjuicios. Sin embargo, la solución planteada no es tal y, por el contrario, contradice la finalidad misma de la mediación y el propósito que tuvieron las partes al acudir a ella, en orden a evitar precisamente la vía judicial y menos la ordinaria.

59 Martí Mingarro, L.: “La mediación civil y mercantil en la nueva Ley 5/2012, de 6 de julio”, en Revista Jurídica de Castilla y León, No 29, enero de 2013, p. 12.

60 Tratándose de laudos extranjeros, su ejecución en Chile se rige por lo dispuesto en los arts. 35 y 36 de la Ley N N $^{\circ} 9.971$, sobre Arbitraje Comercial Internacional, sin necesidad del trámite de execuátur. Chile, además, es parte de la Convención de Nueva York, de 1958, sobre el Reconocimiento y la Ejecución de las Sentencias Arbitrales Extranjeras. 
Por lo anterior, la mayoría de los ordenamientos jurídicos que han regulado la mediación civil y comercial han optado por asignarle mérito ejecutivo al acuerdo ${ }^{61}$, con más o menos formalidades y sea que este se adopte antes o durante el proceso judicial, lo que supone nuevamente un compromiso del Estado legislador que, al menos hasta aquí, permanece ausente en el sistema chileno.

La mediación comercial, en síntesis, es una novedad que toma fuerza en el derecho comparado y que, sin embargo, permanece ausente en la legislación chilena ${ }^{62}$. Se trata, por lo mismo, de una realidad interna que describe incluso el peor de los escenarios, si se piensa en aquellos asuntos en donde las partes en conflicto, en vez de someterlos a la justicia ordinaria o a un proceso arbitral, prefieren reflejar derechamente los activos en disputa como una pérdida en sus balances financieros, resignando a priori toda posibilidad de mantenerlos o, en último término, de reasignarlos o reorganizarlos por la vía de una autocomposición mediada. Semejante panorama, pues, complota contra la competitividad de las empresas económicamente más débiles (principalmente micro y pequeñas empresas), que por lo mismo son las más sensibles y con mayor exposición al conflicto empresarial y a sus efectos económicos de cara a la explotación y subsistencia del giro comercial. Visto en términos agregados, se trata de un fenómeno que afecta a la economía nacional en su totalidad, con pérdidas macroeconómicas que el Estado bien podría evitar - al menos en buena parte- mediante la regulación y fiscalización de un sistema de mediación que, además de ofrecer soluciones que mantienen y promueven las relaciones comerciales entre las partes en conflicto, permite descargar al mismo tiempo a los tribunales de justicia respecto de asuntos que no han debido llegar a ellos.

\section{Conclusiones}

1. Los datos estadísticos, siempre relevantes y valiosos de cara al estudio de fenómenos jurídicos, muestran en este caso concreto cómo la litigiosidad ha ido aumentando paulatina y sostenidamente en Chile, al punto de situarse como la más alta en el ámbito Latinoamericano. Según datos estadísticos obtenidos por

${ }^{61}$ Así por ejemplo, el artículo 517 de la LEC española, modificado por la Ley $N^{\circ}$ 5/2012, de 6 de julio, señala que los acuerdos de mediación elevados a escritura pública de acuerdo con la Ley de mediación en asuntos civiles y mercantiles tendrán mérito ejecutivo. Respecto de los acuerdos adoptados durante el juicio, el art. 25.4 de la misma ley contempla el trámite de la homologación judicial del acuerdo, con idéntica finalidad y resultado. Sobre los mecanismos de cumplimiento del acuerdo de mediación en España puede consultarse a Navas Glembotzky, J. R.: "El enforcement del acuerdo de mediación civil y mercantil en el ámbito internacional: Análisis, Estudio Comparado y Recomendaciones”, en Revista In Dret, No 2, abril de 2014.

${ }^{62}$ Existen actualmente algunas iniciativas de mediación en otras áreas, como la vecinal-comunitaria, penal y escolar; las primeras dos a cargo de los Centros de Mediación del Ministerio de Justicia y de las Corporaciones de Asistencia Judicial, y la última acotada puntualmente a ciertos establecimientos educacionales (vid. http://www.mediacionchile.cl/portal/otras-mediaciones). Importante también ha sido la labor del Centro de Mediación y Arbitraje de la Cámara de Comercio de Santiago -CAM-, que ofrece los servicios de mediación en asuntos empresariales con sujeción a su propio Reglamento (vid. http://www. camsantiago.cl/mediacion.htm). 
el Poder Judicial hace algunos años, aunque extrapolables a la realidad actual del sistema judicial, aproximadamente el $20 \%$ de los ingresos anuales corresponden a causas civiles y comerciales, de estas cerca del $90 \%$ son asuntos de cobranza masiva (procedimientos ejecutivos y gestiones preparatorias de la vía ejecutiva) y el $5 \%$ corresponde a procedimientos ordinarios y sumarios, algunos de muy baja cuantía (desde los \$36.000, según una de las muestras que hemos citado supra).

2. La baja cuantía de algunos asuntos, el costo de litigar, la lentitud del aparato jurisdiccional estatal en general, la eventual desconfianza en la justicia estatal y en el arbitraje como sistema alternativo, los costos adicionales asociados al procedimiento arbitral o, en fin, la decisión de evitar el camino heterocompositivo en aras de conservar la relación de negocios con la contraparte, son factores que disuaden a las empresas a la hora de optar por una solución jurisdiccional de sus conflictos patrimoniales. Como consecuencia necesaria de lo anterior, y según lo muestran los estudios realizados en Europa con ocasión de la Directiva del Parlamento Europeo y del Consejo, No 2008/52/CE de 21 de mayo, Sobre ciertos aspectos de la mediación en asuntos civiles y mercantiles, buena parte de esos asuntos quedan sin solución por cuanto, simplemente, para las empresas involucradas en ellos resulta más rentable castigar los montos comprometidos y reflejarlos contablemente como pérdidas financieras, antes que someterse a un juicio o a un arbitraje que, en último término, echará por tierra cualquier posible relación comercial futura.

Se trata, en fin, de una ineficiencia estructural del sistema de justicia, donde el costo de litigar supera el beneficio de hacerlo, lo que en términos agregados genera también un impacto en la economía en general.

3. Sin perjuicio de lo anterior, y visto el mismo panorama desde la perspectiva del ejercicio de la función jurisdiccional estatal, para los Estados el costo de movilizar y de mantener todo el aparataje judicial, hasta la completa ejecución de la sentencia en conflictos empresariales de baja cuantía (a partir de los $\$ 36.000$ como se dijo) y en casos en donde el principio orgánico de la inexcusabilidad obliga a conocer de asuntos en donde no existe siquiera una controversia real, se traduce en una ineficiencia sistémica y en una deficiente asignación de recursos presupuestarios, con la consiguiente baja rentabilidad social de los mismos.

4. Mientras que en el derecho comparado la mediación de asuntos comerciales y civiles ha sido considerada -e incorporada legalmente- como un mecanismo que apunta al interés colectivo, superador por ende del puro interés individual comprometido en el conflicto inter partes, en Chile no existe una regulación general de la misma ni, hasta aquí, iniciativas legislativas concretas que apunten a su aplicación en términos amplios.

No obstante lo anterior, algunas experiencias puntuales en mediación de asuntos patrimoniales, como el Programa de Mediación Vecinal/Comunitaria impulsado por el Ministerio de Justicia, o el plan piloto de mediación laboral de los años 2002 y 2004, por nombrar las principales, han dado auspiciosos resultados. De igual forma, la experiencia recogida por el "Sistema Nacional de Mediación", a cargo del mismo Ministerio, muestra que al menos en el ámbito familiar -único 
que ofrece datos estadísticos concretos- los resultados del sistema de mediación licitada han sido muy positivos, con altos índices de satisfacción de los usuarios. Distinta ha sido la experiencia con la mediación que lleva a cabo el Centro de Mediación y Arbitraje de la Cámara de Comercio de Santiago, lo que se debe en buena parte a la falta de cooperación de las partes y de sus abogados.

5. La experiencia de algunos países que han normado la mediación mercantil, como también la realidad interna en Chile, muestran que la sola regulación de la misma, sin el respaldo de fórmulas encaminadas a potenciar su uso e incentivar la colaboración efectiva de las partes, no logra los índices de eficiencia que obtienen aquellos sistemas que sí han incorporado tales herramientas.

En este sentido, los caminos elegidos en el ámbito comparado van desde la mediación enteramente voluntaria (sistema español) hasta la obligatoria previa para todos los asuntos de carácter patrimonial (sistema argentino), pasando por estadios intermedios en donde el juez está facultado para someter a las partes a dicho procedimiento, antes o durante el juicio, de oficio o a petición fundada de alguna de ellas (sistema anglosajón del court annexed mediation), con sanciones pecuniarias que apuntan a desincentivar la falta de colaboración leal durante el procedimiento (exoneración de costas a la contraparte, imposición del pago de los gastos de la mediación, honorarios, etc.).

\section{BIBLIOGRAFÍA}

AguirrezÁbal Grünstein, Maite (2013): “Mediación previa obligatoria y acceso a la justicia en el proceso de familia”, en Revista Chilena de Derecho Privado (No 20, julio 2013), pp. 295-308.

Álvarez Moreno, M.T. (2000): “La Mediación empresarial”, en Revista de Derecho Privado (2000), pp. 959-986.

Álvarez Torres, Manuel; Gil Vallejo, Beatriz; Morcillo Jiménez, Jesús (2013): Mediación civil y mercantil (Madrid, Dykinson).

BARONA Vilar, Silvia (2012): Mediación en asuntos civiles y mercantiles en España (Valencia, Tirant lo Blanch).

Bove, Mauro (ed.) (2011): La mediazione per la composizione delle controversie civil e commerciali (Podova, Cedam).

Bustamante Rúa, M. (2010): "Principios del Derecho procesal”, en Derecho procesal contemporáneo (Medellín, Universidad de Medellín).

Cappelletti, M. (1969): "Le grandi tendenze evolutive del proceso civile nel diritto comparato", en Processo e idelogie (Bolonia, Il Moulino).

Casado Román, Javier (2010): "La Mediación Civil y Mercantil en el ámbito del Derecho comunitario", en Diario La Ley ( $\left.\mathrm{N}^{\circ} 7419\right)$.

Ciurana, Andrés (2005): "La mediación civil y mercantil: una asignatura pendiente en España (A propósito de la propuesta de Directiva sobre ciertos aspectos de la mediación en asuntos civiles y mercantiles”, en Actualidad Jurídica (Uría \& Menéndez, Nº 12, diciembre de 2005).

Esplugues Mota, Carlos y Barona Vilar, Silvia (eds.) (2014): Global Perspectives on ADR (Cambridge, Intersentia). 
FALCo, Gianluca y Spina, Giulio (ed.) (2014): La nuova mediazione (Milán, Giuffrè).

GARcía Villaluenga, Leticia y Rogel Vide, Carlos (dir.) (2012): Mediación en asuntos civiles y mercantiles. Comentarios a la Ley 5/2012, Fernández Canales, Carmen, coord. (Madrid, Reus).

García Villaluenga, Leticia, Vázquez de Castro, Eduardo (2013): "La mediación civil en España: luces y sombras de un marco normativo", en Política y Sociedad (Vol. 50, No 1), pp. 71-98.

Gil Nievas, R. (2008): "La Directiva 2008/52/CE del Parlamento Europeo y del Consejo, de 22 de mayo de 2008, sobre ciertos aspectos de la mediación en asuntos civiles y mercantiles", en Actualidad Jurídica ( $\mathrm{N}^{\circ} 768 / 2008$ ).

HeÑ In, Fernando Adrián (2011): "El principio de moralidad en el proceso civil”, en Barberio, Sergio J. y García Solá, Marcela M. (coord.), Principios Procesales, Tomo I (Buenos Aires, Rubinzal-Culzoni), pp. 739-764.

Hualde Manso, Teresa (dir.) (2013): La mediación en asuntos civiles y mercantiles: la transposición de la Directiva 2008/52 en Francia y en España (Madrid, La Ley).

Hunter Ampuero, Iván (2008): "No hay buena fe sin interés: la buena fe procesal y los deberes de veracidad, completitud y colaboración”, en Revista de Derecho, Universidad Austral de Valdivia (Vol. XXI, No 2, diciembre 2008), pp. 151-182.

ImANDJUnTaK, Marcella; Suroto, Valentinus; Nurhayati, Resti (2014): Capítulo “Indonesia”, en Esplugues Mota, Carlos y Barona Vilar, Silvia (eds.), Global Perspectives on ADR (Cambridge, Intersentia).

López-Barajas Perea, Inmaculada (2010): "La mediación civil y mercantil y sus garantías: un paso más en la creación de un espacio judicial europeo”, en Revista General de Derecho Europeo $\left(\mathrm{N}^{\circ} 27\right)$.

López Jara, Manuel (2012): "Incidencia del nuevo procedimiento de mediación en el proceso civil. A propósito del Real Decreto-Ley 5/2012, de 5 de marzo, de mediación en asuntos civiles y mercantiles", en Diario La Ley, Sección Doctrina ( $N^{\circ} 7857,14$ de mayo de 2012, año XXXIII, Ref. D-199).

MARín Hita, Luis (coord.) (2013): Comentarios a la Ley de mediación en asuntos civiles y mercantiles (Madrid, ePraxis).

MARTí Mingarro, Luis (2013): “La mediación civil y mercantil en la nueva Ley 5/2012, de 6 de julio", en Revista Jurídica de Castilla y León ( N $^{\circ} 29$, enero 2013).

NaVAs Glembotzky, Juan Ramón (2014): "El enforcement del acuerdo de mediación civil y mercantil en el ámbito internacional: Análisis, Estudio Comparado y Recomendaciones", en Revista para el análisis del derecho ( $\mathrm{N}^{\circ}$ 2). Disponible en http://www.indret.com/pdf/1054__es.pdf.

Palomo Vélez, Diego, Valenzuela Villalobos, Williams (2012). "Descarte de la inconstitucionalidad de la obligatoriedad de la mediación prejudicial que establece la Ley $\mathrm{N}^{\circ} 19.966$ : lectura crítica de la sentencia del Tribunal Constitucional", en Ius et Praxis (año 18, $\mathrm{N}^{\circ}$ 2), pp. 387-426.

Palomo Vélez, Diego (2013): "Las cargas probatorias dinámicas: ¿es indispensable darse toda esta vuelta?", en Revista Ius et Praxis (año 19, No 2).

Peyrano W., Jorge (2011): "El principio de colaboración procesal”, en Barberio, Sergio J. y García Solá, Marcela M. (coord.), Principios Procesales, Tomo I (Buenos Aires, RubinzalCulzoni), pp. 399-408.

Pintos Santiago, Jaime (2014): “Concepto y delimitación normativa del actual sistema general de mediación civil y mercantil”, en Diario La Ley ( $\left.\mathrm{N}^{\circ} 8278\right)$.

Pissler, Benjamin (2007): "Mediation in China", en Hopt y Steffek (eds.), Mediation (Tübingen, Mohr Siebeck). 
Trigo Sierra, Eduardo y Moya Fernández, Antonio José (2012): "La mediación civil y mercantil en España y en el derecho comparado: a propósito del Real Decreto-Ley 5/2012”, en Actualidad Jurídica Uría E Menéndez ( $\left.\mathrm{N}^{\circ} 32\right)$, pp. 102-112.

VARGAS, Macarena (2008): "Mediación Obligatoria: Algunas razones para justificar su incorporación”, en Revista de Derecho (Universidad Austral de Valdivia) (Vol. 21, No 2), pp. 183-202. 